\title{
O brincar como recurso terapêutico à criança com câncer: relato de experiências
}

\author{
Alessandra Zimmerman \\ cozalessandra@gmail.com \\ Gabriela Christofari \\ gabizinha_christofari@hotmail.com
}

Mônica Sperb

monicasperb@hotmail.com

Gabriella Koltermann

gabikoltermann@gmail.com

Paula Moraes Pfeifer

paulabmpfeifer@gmail.com

Alberto Manuel Quintana

albertom.quintana@gmail.com

Universidade Federal de Santa Maria | Brasil

Camila Peixoto Farias

pfcamila@hotmail.com

Universidade Federal de Pelotas | Brasil

\section{Resumo}

O presente artigo visa demonstrar a importância do brincar na vida de crianças internadas para tratamento oncológico a partir do relato de experiências de participantes de um projeto de extensão no Centro de Tratamento Oncológico-Hematológico de um hospital público no interior do Rio Grande do Sul. O projeto procura proporcionar um ambiente saudável no contexto de hospitalização por meio do brincar. As experiências na interação lúdica com as crianças revelam a importância do brincar ao auxiliar a criança em tratamento a elaborar conflitos e viver os aspectos saudáveis da infância.

\section{Palavras-chave}

Brincar; crianças; hospitalização. 


\section{Introdução}

O câncer contempla um grupo diversificado de doenças que se caracterizam pelo crescimento desordenado de tecidos e órgãos (FONSECA, 2010). Além de ser uma doença crônica que apresenta riscos à vida da pessoa, as neoplasias representam o desconhecido, o perigoso, o sofrimento, a dor e a culpa, bem como sentimentos de perda e morte (COSTA; COHEN, 2012; MALTA; SHALL; REIS; MODENA, 2009). Esta doença, pelas inúmeras alterações que acarreta ao dia a dia do paciente e de seus familiares, é geradora de grande sofrimento, já que adia diversos planos e traz inúmeras restrições a esses indivíduos.

A criança acometida pelo câncer necessita submeter-se a um tratamento bastante invasivo, penoso e doloroso, implicando em uma imagem de "frágil", "dependente", "paciente" e "doente", a qual se opõe ao ideal contemporâneo de corpo saudável (COSTA; COHEN, 2012). Sendo o câncer uma doença acompanhada de estigmas negativos, tornase difícil encará-lo em crianças, já que estas são alvo de expectativas positivas desde antes de nascerem. Além disso, pela possibilidade do tratamento fracassar, o futuro torna-se incerto (MELLO; VALLE, 2010).

Tendo em vista este contexto, ao integrar-se à unidade hospitalar para realizar o tratamento, a criança com diagnóstico de câncer se encontra despreparada para conviver com a doença, hospitalização e suas vicissitudes. Assim, é de suma importância oferecer a esta apoio e intervenções, que proporcionem uma compreensão da doença que desta se apropriou sem ter-lhe dado chance de escolha (MOTTA; ENUMO, 2004). Neste sentido, o brincar, na condição de atividade essencial para o desenvolvimento das crianças, pode se constituir em uma experiência positiva à criança com câncer, no que, na brincadeira, aspectos das realidades externa e interna desta são abarcados e a ressignificação das situações reais da vida pode ocorrer.

Neste tocante, o brincar pode-se consistir em atividade que proporcione conforto às crianças hospitalizadas, sendo que este será relevante independente da idade da criança ou da severidade da doença (ÅNGSTRÖM-BRÄNNSTRÖM; NORBERG, 2014). As atividades lúdicas, por exemplo, auxiliam a criança a dar sentido ao processo de constituição enquanto sujeito, já que estará se valendo de algo que lhe é próprio, o seu imaginário, para se colocar diante da realidade que cria brincando (LOPES; BERNARDINO, 2011; WINNICOTT, 1975). 
A partir da análise da produção científica proposta por Azevêdo (2011) sobre o brincar da criança com câncer no hospital, constatou-se os benefícios do lúdico nesse contexto, por auxiliar no enfrentamento da doença, suas repercussões, e minimizar os efeitos do processo de hospitalização. Além disso, Winnicott (1982) propõe que através do brincar as crianças conseguem dominar angústias e tornam-se capazes de alterar o ambiente em que se encontram de forma a se aproximar da realidade cotidiana.

Para que o brincar seja possibilitado no contexto da internação, entende-se que processos de ambientoterapia são essenciais, visto que as atividades desenvolvidas pelas crianças na comunidade hospitalar devem estar integradas ao processo terapêutico como tal, funcionando como elemento do tratamento. A ambientoterapia consiste na inclusão de aulas, espaços de recreação e interações entre as crianças, os adultos e entre adultos e crianças, de modo que as relações interpessoais estabelecidas dentro do hospital se constituam em caráter curativo (BLAYA, 1963; OSÓRIO, 1975).

Dessa forma, frente ao contexto do câncer que envolve muitas angústias, sofrimentos, desafios e constante necessidade de enfrentamento, a brincadeira e o lúdico possuem papéis imprescindíveis no auxílio do enfrentamento da doença e suas repercussões. Objetiva-se por meio deste artigo, portanto, contribuir para uma melhor compreensão das vivências da criança em tratamento do câncer, permitindo impulsionar intervenções, a partir do brincar, que lhes ofereçam o auxílio necessário na elaboração da doença e suas vicissitudes, visando ao seu bem-estar.

\section{Método}

0 presente artigo trata-se de um estudo descritivo, cujo caráter é de relato de experiência, em que se apresentam as atividades que integram o projeto de extensão "BRINCAR: Projeto de promoção de saúde a crianças com câncer em internação hospitalar". Este projeto tem o intuito de proporcionar um ambiente em que o brincar seja possível e que permita à criança em tratamento elaborar conflitos e manter sua essência infantil, apesar das adversidades da doença, contribuindo para o seu bem-estar. Para tanto, dispõe-se de uma equipe de estudantes de graduação em psicologia que, em duplas, oferecem acompanhamento semanal a tais crianças, em alguns turnos da semana, fornecendo-as um olhar atento. Os participantes do projeto contam com 
supervisões acadêmicas semanais, onde discutem experiências, relatam dificuldades encontradas e, principalmente, planejam atividades.

As atividades do projeto de extensão são pautadas pelos princípios da ambientoterapia (BLAYA, 1963; OSÓRIO, 1975) e desenvolvidas na brinquedoteca de um Centro de Tratamento Oncológico-Hematológico, em hospital público no interior do Rio Grande do Sul. O presente artigo refere-se às interações desenvolvidas durante o período de dois anos. Em relação aos aspectos éticos, ressalta-se que estes foram contemplados em sua totalidade, conforme as normas e diretrizes regulamentadoras de pesquisas envolvendo seres humanos, previstas na Resolução 466/2012 (BRASIL, 2012).

Destaca-se que, neste artigo, os nomes das crianças envolvidas serão apresentados apenas por letras, escolhidas de maneira aleatória, a fim de garantir o sigilo destas. As discussões dos resultados, a seguir, pautam-se nas observações de diários de campo de quatro participantes do projeto, acerca dos acontecimentos durante as interações lúdicas com as crianças, exemplificadas em situações, falas e reações.

\section{Resultados e discussão}

$\mathrm{O}$ ato de brincar promove o autoconhecimento, o conhecimento do outro e das situações reais que se apresentam. No brincar da criança, a realidade do cotidiano pode ser tanto vivenciada, como também negada. É o caso de, no contexto do câncer, negar-se a possibilidade de morte (MELO; VALLE, 2010). No contato realizado no leito de A (masculino, 10 anos), este se encontrava jogando o chamado "Jogo da vida". Em certo momento, a criança para espontaneamente de jogar, indagando: "Imagina se fosse o jogo da morte?! Todas as crianças morreriam". A partir do exemplo citado, percebe-se que o jogo contribui para que a criança expresse suas ansiedades frente à ameaça da morte.

Para a criança, estar doente pode significar encontrar-se impedida de realizar as atividades que lhe são fonte de prazer ou que faziam parte de seu cotidiano anterior à internação. Junto a isso, há a necessidade do afastamento do lar, fazendo com que a doença passe a ser significada como um fator de separação dos membros da família, amigos, escola e atividades esportivas (MALTA; SHALL; REIS; MODENA, 2009; GRIFFITHS; SCHEWEITZER; YATES, 2011). O peso social da doença, muitas vezes, se intensifica quando a criança volta para o ambiente escolar. 0 seu corpo, agora 
enfraquecido, mostra sequelas que são acentuadas pelo olhar do outro, podendo haver sofrimento frente aos preconceitos advindos dos pares (ROLIM; GÓES, 2009). B (feminino, 8 anos) evidencia estes sentimentos quando conversa com a mãe, na presenta de uma estudante, sobre a vergonha em frequentar a escola após ter perdido os cabelos.

$\mathrm{Na}$ interação com C (feminino, três anos), torna-se claro, desde o início, que a brincadeira dizia respeito a si: todas as bonecas Barbie possuíam seu nome, incluindo o boneco Ken, cujo nome masculino foi facilmente convertido ao feminino. Enquanto os bonecos Barbie e Ken andavam de carro, Ken machuca sua perna. Quando questionada sobre como o boneco havia se machucado, a menina responde "Não sei [...]. Ele tava saindo do carro e, do nada, se machucou". Conforme Rodrigues e Camargo (2003) o câncer infantil por vezes adota formas semelhantes a outras doenças comuns e menos graves na infância ou, inclusive, processos fisiológicos presentes no desenvolvimento normal da criança. Assim, o diagnóstico do câncer pode vir a ser tardio. Dessa forma, é possível que a constatação do boneco Ken se machucar "do nada", como constatado por C, remeta ao sentimento de que tudo estava aparentemente bem em sua vida e, de repente, algo grave ocorreu.

Uma forma da criança lidar com aspectos traumáticos em seu psiquismo pode ser através da repetição de cenas e movimentos. 0 brincar de "faz de conta" pode funcionar como trabalho de elaboração na tentativa de simbolizar e transformar os conteúdos internos e suas fantasias (QUEIROZ, 2011). D (masculino, quatro anos), em seu brincar com alguns carrinhos e peças, representou o contexto de cuidado oferecido por sua mãe, que lhe acompanhava durante a internação. Ao brincar com uma peça de jogo, a qual considerou como um ônibus, o menino em determinado momento relata a necessidade de uma ponte para a passagem do ônibus. Este afirma que tal ponte estava ausente e, portanto, a "mãe do ônibus" viria para lhe ajudar a passar pelo caminho.

Conforme os desdobramentos apontados, como o afastamento das atividades do cotidiano e das pessoas que dele faziam parte, percebe-se também que o paciente oncológico encontra outras diversas novidades na rotina hospitalar a qual é submetido e com as quais precisa lidar. E (feminino, três anos) revive, através do brincar, com uma das estudantes, uma das inúmeras situações vivenciada durante a internação. Ao oferecer um alimento e a estudante recusar, a criança pergunta, carinhosamente: "Por 
quê? Tá enjoadinha?" - Perguntas realizadas constantemente pela enfermaria às crianças hospitalizadas, no que recusam algum alimento.

Assim, é comum que crianças internadas e sujeitas a determinados procedimentos se engajem em brincadeiras que os envolvam. Estas, por exemplo, participam ativamente dos seus cuidados de saúde, sendo capazes de, no brincar, conferir sentido e significados às próprias experiências, além de terem uma interpretação da realidade através da própria perspectiva (BJORK; NORDSTROM; HALLSTROM, 2006; GRIFFITHS; SCHEWEITZER; YATES, 2011). Isto se evidencia na brincadeira de $\mathrm{F}$ (feminino, três anos) em que a menina se apresenta com uma preocupação muito grande relacionada às bonecas, as quais devem estar calçando sapatos. A menina parece refletir no brincar o quanto de si é cobrado para que não se mantenha com os pés no chão, devido à baixa imunidade, tão característico da doença. $\mathrm{A}$ menina também brinca de aplicar injeções e realizar curativos na boneca, sua paciente, além de colocar no rosto desta uma máscara igual a que costuma utilizar.

Também, evidencia-se que a grande quantidade de exames que a criança enfrenta diariamente, no contexto hospitalar, leva a necessidade de habituar-se a um lugar que se apresenta como novo e ameaçador, composto por inúmeros profissionais de saúde com os quais terá de se relacionar durante o tratamento (ALCADE, 2005). A significação da nova rotina e aceitação das novas pessoas é um processo necessário para o bom desenvolvimento do tratamento e a brincadeira pode auxiliar neste processo. J (feminino, quatro anos), por exemplo, consegue demonstrar seus sentimentos de desconforto e inadequação ao contexto de internação, através do desenho de um pato, ao afirmar que era existia ali um patinho feio e que ele estava triste. Já K (feminino, 13 anos), evidencia o carinho por uma profissional de saúde, a qual voltara de férias, ao dizer: "Tia, quanto tempo! Senti tanto a tua falta aqui [...]".

Percebe-se o quanto o brincar promove um contexto de significação de vivências, as quais auxiliam a criança a reconhecer-se na e adaptar-se à nova realidade. De acordo com Winnicott (1975, p. 80) é "somente no brincar, que o indivíduo, criança, ou adulto, pode ser criativo e utilizar sua personalidade integral: e é somente sendo criativo que o indivíduo descobre o eu (self)". Este pensamento se reflete na repercussão positiva que o brincar possui para G (masculino, três anos). 0 menino encontra-se, inicialmente, triste e zangado, até que uma estudante desenha um rabisco num papel, solicitando que 
a criança desse continuidade ao "desenho", iniciando um jogo que o incentiva a interagir. Aos poucos, o jogo permite o alívio de resistências e permite o aflorar da espontaneidade. Nota-se que, em situações como a descrita, o brincar exerce um papel terapêutico, em que a criança experiência um estado de abertura à criatividade, à espontaneidade e à interação com outras pessoas.

Neste tocante, Winnicott (1975) traz a noção de espaço potencial, o qual descreve na relação entre mãe e bebê, promovendo um lugar onde o brincar é possível e onde a criança seja capaz de gozar de suas experiências de união entre a onipotência e o controle do real. Este é um espaço regido por leis próprias, que não cede por completo nem às exigências internas nem às externas e, por isso, liberta-se de tensões (ROMÃODIAS; NOLACI-DA-COSTA, 2012). A brincadeira de H (masculino, três anos) e I (masculino, três anos) exemplifica este espaço, no que ambos mantem um diálogo animado, mas ininteligível aos ouvidos dos demais. Percebe-se o quanto um espaço potencial ali se instaurou, permitindo que o brincar espontâneo fosse possível, visto que as crianças se valeram de leis criadas na própria interação, no que tange aos modos de comunicação entre si, que as permitiram um brincar livre de exigências.

Percebe-se, a partir das experiências relatadas, que o brincar entre diferentes pessoas que interagem juntas, provoca uma ação terapêutica que contribui positivamente ao desenvolvimento integral da criança, sendo importante principalmente no contexto de adoecimento e internação (AZEVÊDO, 2011; BORGES; NASCIMENTO; SILVA, 2008; MELLO; VALLE, 2010; MOTTA; ENUMO, 2004). Nesse sentido, faz-se essencial, conforme salienta Winnicott (1975), trazer de volta a capacidade de brincar da criança adoecida, visto que ela, muitas vezes, não se mostra capaz disso. Portanto, confere-se como um desafio ao estudante extensionista adentrar ao mundo da fantasia, reaprender a brincar e tornar o lúdico interessante à criança.

\section{Considerações Finais}

O câncer é uma doença geradora de grande sofrimento para o paciente diagnosticado com a doença, devido às inúmeras implicações que acarreta à vida deste sujeito. A criança com diagnóstico de câncer não está preparada para encarar a doença, as mudanças na rotina, bem como o tratamento penoso e invasivo, o que pode lhe causar 
angústia. Deve-se a isto a importância do brincar, por meio do qual a criança pode ressignificar o cotidiano da internação através da expressão de seus receios e conflitos.

A brinquedoteca, pautada nos princípios da ambientoterapia, consiste, portanto, em um ambiente saudável de apoio que auxilia a criança com câncer na compreensão de suas vivências. Este espaço recreativo abarca a expressão de sentimentos e angústias, sendo importante também para os familiares que acompanham as crianças. Ainda, é um local que estimula a socialização da criança, por proporcionar trocas e partilhas tanto de brinquedos como de experiências. Ainda que vivenciem um período difícil, tais crianças continuam a manter sua essência de curiosidade e busca.

O projeto de extensão "BRINCAR: Promoção de saúde a crianças com câncer em internação hospitalar", visa proporcionar este ambiente favorável ao desenvolvimento das crianças acometidas pelo câncer ao reconhecer a importância do brincar e enfatizar os aspectos saudáveis da infância, frente ao ambiente hospitalar. Ao constatar que por meio do brincar as crianças tornam-se mais capazes de expressar seus sentimentos, conflitos e angústias ocasionados pela doença, busca-se oferecer uma escuta e olhar diferenciados diante destes aspectos, a fim de lhe servir como mais uma fonte de apoio no enfrentamento do câncer. Por fim, espera-se que as discussões trazidas neste artigo possam repercutir em benefícios para a sociedade, ampliando conhecimentos sobre a temática, oferecendo subsídios para pensar na aplicabilidade das práticas em contextos semelhantes, bem como suscitando questões para pesquisa na área da oncologia infantil, vinculada à prática do profissional na área da saúde.

\section{Referências}

ALCADE, F. Afrontamiento del cáncer infantil. Boletín El Dolor, v. 14, p. 24-29, 2005. Disponível em:

http://www.ached.cl/upfiles/revistas/documentos/43a961e9d98f9_05_afrontamiento_ cancer.pdf. Acesso em: 05 mar. 2017.

ÄNGSTRÖM-BRÄNNSTRÖM, C.; NORBERG, A. Children Undergoing Cancer Treatment Describe Their Experiences of Comfort in Interviews and Drawings. Journal of Pediatric Oncology Nursing, v. 31, p. 135-146, 2014. Disponível em: https://www.ncbi.nlm.nih.gov/pubmed/24651546. Acesso em: 30 jan. 2017.

AZEVÊDO, A. V. S. O brincar da criança com câncer no hospital: análise da produção científica. Estudos de Psicologia, v. 28, p. 565-572, 2011. Disponível em: 
http://www.scielo.br/scielo.php?script=sci_arttext\&pid=S0103-166X2011000400015. Acesso em: 30 jan. 2017.

BJORK, M.; NORDSTROM, B.; HALLSTROM, I.. Needs of Young children with cancer during their initial hospitalization: an observational study. Journal of Pediatric Oncology Nursing, v. 23, p. 210-219, 2006. Disponível em:

https://www.ncbi.nlm.nih.gov/pubmed/16766686. Acesso em: 12 jan. 2017.

BLAYA, Marcelo. Ambientoterapia: Comunidade Terapêutica. Arquivos de NeuroPsiquiatria, v. 21, p. 39-43, 1963. Disponível em: http://www.scielo.br/pdf/anp/v21n1/07.pdf. Acesso em: 28 jan. 2017.

BORGES, E. P.; NASCIMENTO, M. D. S. B.; SILVA, S. M. M.. Benefícios das atividades lúdicas na recuperação de crianças com câncer. Boletim Academia Paulista de Psicologia, v. 28, p. 211-221, 2008. Disponível em: http://pepsic.bvsalud.org/pdf/bapp/v28n2/v28n2a09.pdf. Acesso em: 05 mar. 2017.

BRASIL. Conselho Nacional de Saúde. Resolução n. 466 de 12 de dezembro de 2012. Disponível em: http://conselho.saude.gov.br/resolucoes/2012/Reso466.pdf. Acesso em: 20 mai. 2016.

COSTA, M. R. L.; COHEN, R. H. P.. O sujeito-criança e suas surpresas. Trivium - Estudos interdisciplinares, $\quad$ v. 4 , p. 59-64, 2012. Disponível em: https://www.uva.br/trivium/edicoes/edicao-i-ano-iv/artigos-tematicos/o-sujeitocrianca-e-suas-surpresas.pdf. Acesso em: 25 jan. 2017.

FONSECA, M. S.. Colaboración interdisciplinaria em la atención del niño com câncer y su familia. Revista Venezolana de Oncología, v. 22, p. 174-186, 2010. Disponível em: http://www.redalyc.org/articulo.oa?id=375634864003. Acesso em: 23 jan. 2017.

GRIFFITHS, M.; SCHWEITZER, R.; YATES, P.. Childhood Experiences of Cancer: An Interpretative Phenomenological Analysis Approach. Journal of Pediatric Oncology Nursing, v.28, p. 83-92, 2011. Disponível em: https://www.ncbi.nlm.nih.gov/pubmed/20739585. Acesso em 05 mar. 2017.

LOPES, T. J. S.; BERNARDINO, L. M. F.. O sujeito em constituição, o brincar e a problemática do desejo na modernidade. Revista Mal estar e Subjetividade, v. 21, p. 369-395, 2011. Disponível em:

http://pepsic.bvsalud.org/scielo.php?script=sci_arttext\&pid=S151861482011000100014. Acesso em 05 mar. 2017.

MALTA, J.; SCHALL, V.; REIS, J. C..; MODENA, C.. Quando falar é difícil: a narrativa de crianças com câncer. Revista Pediatria Moderna, v. 45, p. 194-198, 2009. Disponível em: http://www.moreirajr.com.br/revistas.asp?fase=r003\&id_materia=4095. Acesso em 25 jan. 2017. 
MELO, L. L.; VALLE, E. R. M.. A brinquedoteca como possibilidade para desvelar o cotidiano da criança com câncer em tratamento ambulatorial. Revista da Escola de Enfermagem da USP, v. 44, p. 517-525, 2010. Disponível em:

http://www.scielo.br/scielo.php?script=sci_arttext\&pid=S0080-62342010000200039. Acesso em 10 jan. 2017.

MOTTA, A. B.; ENUMO, S. R. F.. Brincar no hospital: estratégia de enfrentamento da hospitalização infantil. Psicologia em Estudo, v. 9, p. 19-28, 2004. Disponível em: http://www.scielo.br/pdf/pe/v9n1/v9n1a04.pdf. Acesso em 30 jan. 2017.

OSÓRIO, L. C.. Ambientoterapia na infância e adolescência. Porto Alegre: Editora Movimento, 1975.

QUEIROZ, F. C. A.. Representação no campo do traumático: a enfermidade grave na infância e o impacto sobre o desenvolvimento. Tese (Doutorado). Universidade de São Paulo, Programa de Pós Graduação em Psicologia da Aprendizagem e do Desenvolvimento Humano, São Paulo, 2011.

RODRIGUES, Karla Emília; CAMARGO, Beatriz. Diagnóstico precoce do câncer infantil: responsabilidade de todos. Revista Associação Médica Brasileira, v. 49, p. 29-34, 2003. Disponível em: http://www.scielo.br/pdf/ramb/v49n1/15377.pdf. Acesso em 10 jan. 2017.

ROLIM, C. L. A.; GÓES, M. C. R.. Crianças com câncer e o atendimento educacional nos ambientes hospitalar e escolar. Educação e Pesquisa, v. 35, p. 509-523, 2009. Disponível em: http://www.scielo.br/pdf/ep/v35n3/07.pdf. Acesso em 05 mar. 2017.

ROMÃO-DIAS, D.; NOLACI-DA-COSTA, A. M.. O brincar e a realidade virtual. Caderno de psicanálise-CPRJ, $\quad$ v. $34, \quad$ p. 85-101, 2012. Disponível em: http://pepsic.bvsalud.org/pdf/cadpsi/v34n26/a07.pdf. Acesso em 05 mar. 2017.

WINNICOTT, D. W.. O brincar e a realidade. Rio de Janeiro: Imago, 1975.

_. A criança e o seu mundo. Rio de Janeiro: LTC Editora, 1982.

Playing as a therapeutic resource for children with cancer: Experience report

\section{ABSTRACT}

This article aims to demonstrate the importance of maintaining playing in the lives of children under cancer treatment based on the participants' experience report of an extension project, which occurs in an OncologyHematology Treatment Center of a public hospital in the interior of Rio Grande do Sul. The project aims to provide an environment in the hospitalization context through the play. The experiences in playful interaction with the children reveal the importance of playing to assist the child in treatment to develop conflicts and live the healthy aspects of childhood.

Keywords:

Playing. Children. Hospitalization. 
O brincar como recurso terapêutico à crianças com câncer: relato de experiência

El jugar como recurso terapéutico para los niños con cáncer: Informe de experiencias

\section{RESUMEN}

Este artículo tiene como objetivo demostrar la importancia de jugar en la vida de los niños hospitalizados para el tratamiento del cáncer, a partir de un relato de experiencia de participantes de un proyecto de extensión en el Centro de Tratamiento de Hematolo-Oncología de un hospital público en el interior de Rio
Grande do Sul. El proyecto tiene por objeto proporcionar un ambiente saludable en el contexto de la hospitalización a través de jugar. Las experiencias en la interacción lúdica con los niños ponen de manifiesto la importancia del juego para ayudar al niño en tratamiento de elaborar conflictos y vivir los aspectos saludables de la infancia.

Palabras clave:

Juego. Niños. Hospitalización.

Original submetido em: 16 mar. 2017

Aceito para publicação em: 06 dez. 2017

Sobre os autores:

Alessandra Zimmerman

Mestranda pelo Programa de Pós-Graduação em Psicologia da Universidade Federal de Santa Maria (UFSM); Graduada em Psicologia (UFSM).

\section{Gabriela Christofari}

Mestranda pelo Programa de Pós-Graduação em Psicologia da Universidade Federal de Santa Maria (UFSM); Graduada em Psicologia (UFSM).

\section{Mônica Sperb}

Mestranda pelo Programa de Pós-Graduação em Psicologia da Universidade Federal de Santa Maria (UFSM); Graduada em Psicologia (UFSM).

\section{Gabriella Koltermann}

Mestranda pelo Programa de Pós-Graduação em Psicologia da Universidade Federal do Rio Grande do Sul (UFRGS); Graduada em Psicologia (UFSM).

\section{Paula Moraes Pfeifer}

Psicóloga Clínica no Instituto de Cardiologia da Fundação Universitária de Cardiologia (IC-FUC); Preceptora da Residência Integrada em Saúde: cardiologia (Risc). Mestre em Psicologia da Saúde pela Universidade Federal de Santa Maria (UFSM); Graduada em Psicologia (UFSM).

\section{Alberto Manuel Quintana}

Professor Titular do curso de Psicologia e do Programa de Pós-Graduação em Psicologia da Universidade Federal de Santa Maria (UFSM). Graduado em Psicologia pela Universidad Argentina J F Kennedy; mestre em Psicologia (Psicologia Clínica) pela Pontifícia Universidade Católica do Rio de Janeiro (PUCRJ); doutor em Ciências Sociais, com área de concentração em Antropologia Clínica, pela Pontifícia Universidade Católica de São Paulo (PUCSP) e pós-doutorado pela Universidade Complutense de Madrid. 
O brincar como recurso terapêutico à crianças com câncer: relato de experiência

\section{Camila Peixoto Farias}

Professora do curso de Psicologia da Universidade Federal de Pelotas (UFPel) e professora colaboradora do Programa de Pós-graduação em Psicologia da Universidade Federal de Santa Maria (UFSM). Graduada em Psicologia (UFSM), Mestre e Doutora em Teoria Psicanalítica pelo Programa de Pós-graduação em Teoria Psicanalítica da Universidade Federal do Rio de Janeiro (UFRJ). Pesquisadora do Grupo de Pesquisa Núcleo de Estudos Interdisciplinares em Saúde (UFSM), do Grupo de Pesquisa Psicanálise e Política (UFMG) e do Grupo de Pesquisa Trauma e representação: teoria, clínica e cultura (UFRJ). Membro do Grupo de Trabalho: Psicanálise, subjetivação e cultura contemporânea, da Associação Nacional de Pós-graduação em Psicologia (ANPEP). 